\title{
Using Gum Arabic in Place of Egg Yolk as Cryoprotectant for Cryopreservation of the Buck Semen
}

\begin{abstract}
Background: Egg yolk (EY) is well known to be toxic for buck spermatozoa, which creates restrictions of its use in cryopreservation. Therefore, this study is to compare the effect of different levels of gum Arabic (GA) in an extender on quality and fertility of cryopreserved buck sperm.

Methods: Each ejaculate of six bucks was frozen in Tris with one of concentrations of GA which contained 3, 6, 9 and $12 \mathrm{gm} / 100 \mathrm{ml}$ in place of the EY. Control was Tris extender containing $2.5 \%$ of EY.

Result: A percentages of total motile sperm $(54.92 \% ; P<0.05)$ and progressively motile sperm $(26.22 \% ; P<0.05)$ of semen was frozen in Tris containing $9 \%$ of GA. Similar to control group, the pregnancy rate of does inseminated with extender containing $9 \%$ $(50.0 \%)$ were significantly higher than those of does inseminated with extender containing $6 \%(8.33 \%), 3 \%(0.0 \%)$ and $12 \%(0.0 \%)$. Semen evaluation and fertility rate were similar when replacing the EY with GA in the Tris cryodiluent, after cryopreservation of buck semen. The present study shows that high motility rate of frozen semen and acceptable pregnancy rate can be obtained when using $\mathrm{GA}$ in place of EY for cryopreserving the buck sperm.
\end{abstract}

Key words: Artificial insemination, Buck semen, Cryopreservation, Egg yolk, Gum Arabic.

\section{INTRODUCTION}

Sperm cryopreserved in liquid nitrogen, is a technique to preserve genetic resources and provides some benefits, such as easily shipping of global germ plasma and selective breeding with desirable characteristics (Beir, et al. 2019).

Frozen semen should be frozen at a very low temperature $\left(-196^{\circ} \mathrm{C}\right)$, therefore, it is necessary to extend the semen in appropriate diluents contained cryoprotectants, such as glycerol and EY. However, there were attempts to find alternatives to $E Y$ in cryoprotective media, due to a source of bacterial contamination (Ondřej, et al. 2019). Therefore, it would be better to use a well-defined and pathogen-free alternative, non-animal origin substitute for EY (Singh et al. 2017). In addition, EY of $\geq 3 \%$ is well known to be toxic for buck spermatozoa (Ritar and Salamon, 1982), where the egg yolk coagulating enzyme (EYCE) is a harmful to the sperm cells (Purdy, 2006). Egg yolk is considered a cause of the reduction in the respiration and motility of spermatozoa in bulls were caused by the granules (Ugur et al. 2019) and caused reduction in the accuracy of computer in order to detection of false sperm, which may actually be $E Y$ particles or other debris (García et al. 2017). This caused increasing the percentage of immotile spermatozoa. However, in all animal species, the EY is important part of most semen extenders due to protects the sperm from thermal shock during freezing (Anand, et al. 2014).

Therefore providing a non animal origin, well defined and pathogen free medium for the cryopreservation of semen is highly desired (Muhammet, et al. 2019). In the present study, GA is used as cryoprotectant to preserve buck sperm at low temperature. According to study by Mohamed
Department of Animal Production and Breeding, Faculty of Agriculture and Veterinary, Qassim University, Al-Qassim 51452, Saudi Arabia.

Corresponding Author: Mohamed Ali, Department of Animal Production and Breeding, Faculty of Agriculture and Veterinary, Qassim University, Al-Qassim 51452, Saudi Arabia.

Email: mohamed0_9@yahoo.com

How to cite this article: Ali, M. (2021). Using Gum Arabic in Place of Egg Yolk as Cryoprotectant for Cryopreservation of the Buck Semen. Indian Journal of Animal Research. DOI: 10.18805/ IJAR.B-1373.

Submitted: $14-04-2021 \quad$ Accepted: $15-06-2021 \quad$ Online: 11-09-2021

Ali et al. (2017), a highly quality of post thawed frozen stallion semen was achieved after freezing, when using GA instead of the EY. However, this present study is considered the comparative research related to $\mathrm{GA}$ as an alternative to $\mathrm{EY}$ for the cryopreservation of buck spermatozoa. Therefore, the aim of the current study is to compare the effect of different levels of GA in an extender on quality and fertility of cryopreserved buck sperm.

\section{MATERIALS AND METHODS Animals}

The current study was carried out using six fertile bucks and 58 does (Aradi-Damascus Crossbred) with an age range of 2-4 years from the Research Center in Qassim UniversityAl-Qassim region, Saudi Arabia. All does were clinically healthy at the semiological examination and had given birth at least once before the beginning of the study. 


\section{Semen collection}

Semen was collected using an artificial vagina and then immediately kept in water bath at $37^{\circ} \mathrm{C}$. Semen characterization was achieved, such as color, volume, $\mathrm{pH}$, general motility, percentage motility, concentration and live/ dead ratio. Sperm motility and concentration were estimated with the computer assisted semen analysis system (CASA; ISAS $^{\circledR}$ program, Proiser R+D, Valencia, Spain).

\section{Extenders}

The samples were frozen using Tris extender. The EY $(2.5$ $\mathrm{mL}$; as control group) was replaced with GA (Sigma-Aldrich Company, USA) in different concentrations (3, 6, 9 and $12 \%)$. Every ejaculate of all bucks was treated the same concentration of GA or EY. The GA was heated at $80^{\circ} \mathrm{C}$ for 60 minutes to inactive the enzymes. The Tris extender was prepared using sugars ( $0.625 \mathrm{~g}$ glucose), buffering agents (3.786 $\mathrm{g}$ Tris and $2.172 \mathrm{~g}$ citric acid), $5 \mathrm{~mL}$ glycerol and non-pyrogenic water (added to a volume of $100 \mathrm{~mL}$ ). Measurement of the extender viscosity (cP) was determined by vibroviscometer (model SV-10, Tokyo, Japan) at room temperature. $\mathrm{pH}$ measurement was adjusted at 7-7.2 (HANNA HI 2211, Italy). Measurement of the extender osmolarity ( $\mathrm{mOsmol} / \mathrm{kgH} 2 \mathrm{O}$ ) was determined by osmometer (model 800 CLG, SLAMED, Germany).

\section{Deep freezing}

The semen from each of the six bucks was resuspended with Tris extender containing EY (2.5\%) or AG $(3,6,9$, or $12 \%)$ and glycerol (5\%); the final volume after dilution was one $\mathrm{ml}$ semen to $4 \mathrm{~mL}$ of extender and then cooled to $4^{\circ} \mathrm{C}$ for $75 \mathrm{~min}$. After cooling, diluted semen was evaluated using ISAS and then filled into straws $(0.5 \mathrm{~mL})$. Freezing processes were performed by putting the straw horizontally on the surface of liquid nitrogen at 3-4 cm for 20 minutes. After seven days kept in liquid nitrogen, straws were thawed in a water bath at $37^{\circ} \mathrm{C}$ for $60 \mathrm{~s}$ immediately and then analyzed by the ISAS system.

\section{Assessment of sperm motility}

Cooled diluted semen and frozen semen were examined for a motility pattern using the ISAS ${ }^{\circledR}$ program. A five $\mu \mathrm{L}$ from each diluted semen was placed in a pre-warmed slide. Seven consecutive digitalized images obtained from several fields using a $10 \mathrm{X}$ negative-phase contrast objective were examined for sperm motility analysis. At least 300 spermatozoa per sample were analyzed. Subsequently sperm motility parameters were recorded: total motile spermatozoa (\% TMS), rapid progressively motile sperm (\% PRS), curvilinear velocity (VCL) in $\mu \mathrm{m} / \mathrm{s}$, rectilinear velocity (VSL) in ìm/s, the average path velocity (VAP) in $\mu \mathrm{m} / \mathrm{s}$, straightness index (\% STR), linearity coefficient (\% LIN), oscillation index (\% WOB), amplitude of lateral head displacement ( $\% A L H)$ and beat cross frequency $(\mathrm{Hz}, \mathrm{BCF})$. Spermatozoa with a swimming speed or VAP values below $10 \mu \mathrm{m} / \mathrm{s}$ were considered immotile spermatozoa (IMS).

\section{Cooled and frozen semen evaluation}

Cooled semen and frozen-thawed semen were evaluated for the functionality of the plasma membrane by the Hypoosmotic swelling test (HOST). Twenty $\mu \mathrm{L}$ of semen was added to $2 \mathrm{ml}$ of $125 \mathrm{mOsmol}$ fructose-base solution and then incubated in a water bath at $37^{\circ} \mathrm{C}$ for 50 minutes. Subsequently, one hindered sperm cells were analyzed for the presence or absence of a coiled tail (Fonseca et al. 2005).

The Giemsa staining procedure was used to examine the defected acrosome. The morphologically normal spermatozoa were examined by the nigrosin-eosin stain (Evans and Maxwell, 1987). At least 200 spermatozoa were examined for acrosome defect and defect sperm under a light microscope $(1,000 x)$.

Fluorescent stains such as acridine orange $(\mathrm{AO})$ and propidium iodide $(\mathrm{PI})$ were used to assess cell viability (Halotech DNA, S.L., Spain). Fluorescence green of head sperm occurs when $A O$ is retained within intact cells. PI stain can only bind to and stain cellular DNA in non-living or damaged cells, causing them to have red fluorescence. Three hindered sperm per sample was counted.

\section{Artificial insemination protocol}

Does were synchronized by using sponge (SYNCROPART® sponges contain $45 \mathrm{mg}$ of fluorogestone, Ceva Santé Animale, France) that was inserted intra vaginal for 17 days. At Day 17 the sponge was removed and 300 iu of pregnant mare serum gonadotrophine (SYNCRO PART ${ }^{\oplus}$ PMSG, Ceva Santé Animale, France) was injected intramusculary for each doe. After 50-60 hours from sponge removal, the inseminations were performed intracervical using $600 \times 10^{6}$ total spermatozoa/insemination. All does were examined for pregnancy diagnosis using ultrasonography 30 days after insemination.

\section{Statistical analysis}

Descriptive analyses were determined for the evaluated variables: total motility (MT), progressive motility (PMS), VCL, VSL, VAP, STR, LIN, WOB, ALH, BCF, acrosome integrity, vitality, HOST and morphological defect. One-way analysis of variance (ANOVA) were performed for statistical comparisons between groups. Analysis of the normal distribution of data was examined with the KolmogorovSmirnov test (SPSS, version 16). The data were considered statistically different if $P<0.05$. Data were expressed as the means and SEM.

\section{RESULTS AND DISCUSSION}

Sperm parameters, including motility, viability, plasma membrane integrity, normal morphology and acrosome integrity, were noted in samples that were cooled in Tris extender containing GA and evaluated and presented in Table 1. Extenders with 3, 6 and $9 \%$ of GA were high efficient in sperm motility than extender with $12 \%$. A similar result of high sperm motility was found in EY extender compared 
Using Gum Arabic in Place of Egg Yolk as Cryoprotectant for Cryopreservation of the Buck Semen

Table 1: Motility and viability parameters of buck semen were stored at $4^{\circ} \mathrm{C}$ for $75 \mathrm{~min}$.

\begin{tabular}{lccccc}
\hline Parameter & GA3 & GA6 & GA9 & GA12 & EY \\
\hline TMS $(\%)$ & $88.52 \pm 4.30^{\mathrm{a}}$ & $87.06 \pm 2.90^{\mathrm{a}}$ & $92.53 \pm 2.39^{\mathrm{a}}$ & $66.83 \pm 8.28^{\mathrm{b}}$ & $78.30 \pm 5.70^{\mathrm{a}}$ \\
PRS $(\%)$ & $69.04 \pm 6.97^{\mathrm{a}}$ & $68.86 \pm 4.90^{\mathrm{a}}$ & $72.13 \pm 5.76^{\mathrm{a}}$ & $35.70 \pm 9.06^{\mathrm{b}}$ & $61.65 \pm 1.85^{\mathrm{a}}$ \\
VCL $(\mu \mathrm{m} / \mathrm{s})$ & $99.04 \pm 6.06^{\mathrm{a}}$ & $97.62 \pm 3.47^{\mathrm{a}}$ & $97.68 \pm 3.60^{\mathrm{a}}$ & $73.38 \pm 7.47^{\mathrm{b}}$ & $94.20 \pm 4.7^{\mathrm{a}}$ \\
VSL $(\mu \mathrm{m} / \mathrm{s})$ & $24.92 \pm 1.68^{\mathrm{a}}$ & $24.30 \pm 0.69^{\mathrm{a}}$ & $24.53 \pm 0.93^{\mathrm{a}}$ & $21.33 \pm 1.45^{\mathrm{b}}$ & $24.90 \pm 0.06^{\mathrm{a}}$ \\
VAP $(\mu \mathrm{m} / \mathrm{s})$ & $48.70 \pm 3.05^{\mathrm{a}}$ & $48.50 \pm 1.55^{\mathrm{a}}$ & $50.30 \pm 2.22^{\mathrm{a}}$ & $40.25 \pm 3.21^{\mathrm{b}}$ & $44.30 \pm 0.01^{\mathrm{a}}$ \\
LIN $(\%)$ & $25.26 \pm 1.27^{\mathrm{b}}$ & $25.03 \pm 0.43^{\mathrm{b}}$ & $25.21 \pm 0.54^{\mathrm{b}}$ & $30.01 \pm 2.14^{\mathrm{a}}$ & $25.50 \pm 0.22^{\mathrm{ab}}$ \\
STR (\%) & $50.86 \pm 2.17^{\mathrm{ab}}$ & $50.03 \pm 0.96^{\mathrm{ab}}$ & $48.35 \pm 0.50^{\mathrm{b}}$ & $53.43 \pm 2.09^{\mathrm{a}}$ & $49.20 \pm 0.01^{\mathrm{ab}}$ \\
WOB (\%) & $49.06 \pm 0.99^{\mathrm{b}}$ & $50.08 \pm 0.73^{\mathrm{b}}$ & $51.91 \pm 0.65^{\mathrm{b}}$ & $55.43 \pm 2.04^{\mathrm{a}}$ & $55.20 \pm 0.00^{\mathrm{a}}$ \\
ALH (\%) & $3.80 \pm 0.56^{\mathrm{ab}}$ & $4.38 \pm 0.12^{\mathrm{a}}$ & $4.38 \pm 0.18^{\mathrm{a}}$ & $3.58 \pm 0.23^{\mathrm{b}}$ & $3.60 \pm 0.02^{\mathrm{ab}}$ \\
BCF $(\mathrm{Hz})$ & $4.76 \pm 0.28^{\mathrm{b}}$ & $6.00 \pm 0.19^{\mathrm{ab}}$ & $6.18 \pm 0.24^{\mathrm{ab}}$ & $7.26 \pm 0.99^{\mathrm{a}}$ & $4.20 \pm 0.06^{\mathrm{b}}$ \\
Vital $(\%)$ & $72.50 \pm 4.51$ & $80.27 \pm 1.39$ & $74.87 \pm 1.93$ & $67.83 \pm 2.77$ & $75.54 \pm 2.30$ \\
HOST (\%) & $76.27 \pm 2.76$ & $80.00 \pm 0.00$ & $65.95 \pm 0.95$ & $63.58 \pm 9.45$ & $67.87 \pm 1.21$ \\
Total defect (\%) & $8.50 \pm 0.00$ & $3.10 \pm 0.00$ & $6.80 \pm 0.30$ & $7.40 \pm 0.00$ & $8.76 \pm 3.50$ \\
Acrosome integrity (\%) & $78.07 \pm 0.00^{\mathrm{b}}$ & $79.72 \pm 1.08^{\mathrm{b}}$ & $85.44 \pm 0.39^{\mathrm{b}}$ & $79.45 \pm 0.41^{\mathrm{b}}$ & $91.50 \pm 4.50^{\mathrm{a}}$ \\
\hline
\end{tabular}

a, b, ab subscript represent significant difference at $P<0.05$ between groups in the same raw.

with $12 \%$ GA extender. VCL, VSL and VAP values were significantly higher in GA (3, 6 and $9 \%)$ and $E Y$ compared to extender containing $12 \%$ of GA. Tris extender with $12 \%$ of GA was highly significant in LIN, STR, WOB and BCF compared to others. There is no significant different among groups in vitality rate, plasma membrane integrity and morphology defects. The acrosome integrity in extenders containing EY $(2.5 \%)$ was greater $(P<0.05)$ than that of sperm that was cooled in extenders containing $\mathrm{GA}(3,6,9$ and $12 \%)$.

Extenders should be contain cryoprotectants to protect the sperm against cooled shock such as, egg yolk, egg plasma, skim milk, milk by products, or chemicals for regulation of osmolarity and $\mathrm{pH}$. This research showed that maintaining the sperm motility and progressive motile sperm during cooling and freezing temperature could be achieved more favorably in the diluents containing GA than the diluent containing $E Y$ for buck semen. However, this study agrees with the study using GA in cryopreservation of stallion semen (Mohamed Ali et al. 2017). Gum Arabic is complex, comprised of polysaccharide, and a branch polymer consisting of galactose, rhamnose, arabinose, and glucuronic acid (Montenegro, et al. 2012). Gum Arabic has been better than glycerol, Me2SO, or lactose in cryoprotecting T2 bacteriophage and it has also been successfully utilized for the cyanobacterium S. platensis (Hubalek, 2003). Gum Arabic is easily soluble in water and forms solutions over a wide range of concentrations. The mechanism of action of polysaccharides in promoting frozen stability is related to the control of the amorphous matrix surrounding the ice crystals (Lopez et al. 2005). The GA has a large polysaccharide structure result in used as an extracellular cryoprotectant.

After deep-freezing, parameters of motility and viability of buck sperm are shown in Table 2. Tris extender containing GA of $9 \%$ showed a significantly higher in total sperm motile sperm compared to extenders containing GA of 3, 6 and $12 \%$ or $2.5 \%$ of EY. While progressive motile was significantly higher in $9 \%$ of GA and EY compared to others. The probability is due to homogeneity of the extender in $\mathrm{pH}$, viscosity and osmolarity which might be better stability in that extender. In addition this feature provides greater energy support for survival and a sperm cell movement. However, alterations in permeability, functionality and metabolism of sperm cell, resulting in changes of the motility and fertilizing ability, are due to changes in organization of the plasma membrane fluid mosaic (Amann and Graham, 1993). Although the mechanism of sperm protection by using GA is unknown. However, more work is needed to know how the GA protects sperm during freezing. Another factor for the survival of sperm cells and continues positive correlation with ATP concentration during storage is the amount of energy reserves contained in the extender. In the present study, $6 \%$ and $9 \%$ of GA were the optimal concentrations to keep the average velocity (VCL, VSL and VAP). The viscosity of $12 \%$ GA was about $50 \%$ and $80 \%$ more than that of $9 \% \mathrm{GA}$ and $\mathrm{EY}$, respectively, being the most effective trait ruling sperm motility (Mohamed Ali et al. 2018). However, there was no significantly difference among the extenders after cooling or freezing. Osmolarity of Tris extender contained GA or EY was approximately the same values of $\mathrm{pH}$ range between 7.0 - 7.2 as shown in Table 3. Obviously, $>9 \%$ primarily affected fast swimming sperm cells and impede spermatozoa with a velocity slightly above $45 \mu \mathrm{m} / \mathrm{s}$. Thus, the percentage of immotile spermatozoa $(<10 \mu \mathrm{m} /$ $\mathrm{sec}$ ) increased with the increase of viscosity. This phenomenon might confirm no fertility resulted of the use of $12 \%$ GA extenders in the current study. The ultimate explanation for this impediment of fertility is the high viscosity negatively affected the sperm survival before or during storage in liquid nitrogen. It has been established that the viscosity of the extender affects the pattern of sperm motion by the addition of Ficoll, carboxy methyl cellulose (CMC), methylcellulose, EY or GA (Amann and Hammerstedt, 1980, Hirai et al. 1997, Mohamed Ali et al. 2017). In the present 
Using Gum Arabic in Place of Egg Yolk as Cryoprotectant for Cryopreservation of the Buck Semen

Table 2: Motility and viability parameters and pregnancy rate of buck semen was frozen in liquid nitrogen.

\begin{tabular}{lccccc}
\hline Parameter & GA3 & GA6 & GA9 & GA12 & EY \\
\hline TMS $(\%)$ & $15.56 \pm 0.85^{\mathrm{b}}$ & $33.60 \pm 4.09^{\mathrm{b}}$ & $54.92 \pm 8.50^{\mathrm{a}}$ & $17.83 \pm 4.00^{\mathrm{b}}$ & $40.40 \pm 2.60^{\mathrm{ab}}$ \\
PRS $(\%)$ & $6.50 \pm 1.40^{\mathrm{b}}$ & $14.72 \pm 2.71^{\mathrm{b}}$ & $26.22 \pm 5.35^{\mathrm{a}}$ & $6.83 \pm 1.83^{\mathrm{b}}$ & $20.13 \pm 2.86^{\mathrm{a}}$ \\
VCL $(\mu \mathrm{m} / \mathrm{s})$ & $50.33 \pm 1.33^{\mathrm{b}}$ & $62.37 \pm 3.44^{\mathrm{a}}$ & $52.75 \pm 2.35^{\mathrm{b}}$ & $49.56 \pm 3.64^{\mathrm{b}}$ & $52.80 \pm 4.20^{\mathrm{b}}$ \\
VSL $(\mu \mathrm{m} / \mathrm{s})$ & $14.53 \pm 0.43$ & $14.37 \pm 1.30$ & $17.12 \pm 1.15$ & $14.26 \pm 0.71$ & $14.56 \pm 0.53$ \\
VAP $(\mu \mathrm{m} / \mathrm{s})$ & $27.43 \pm 0.73^{\mathrm{ab}}$ & $30.50 \pm 1.61^{\mathrm{ab}}$ & $31.62 \pm 1.67^{\mathrm{a}}$ & $26.66 \pm 1.56^{\mathrm{b}}$ & $28.06 \pm 1.63^{\mathrm{ab}}$ \\
LIN $(\%)$ & $28.86 \pm 0.06^{\mathrm{a}}$ & $23.20 \pm 2.32^{\mathrm{b}}$ & $32.40 \pm 0.90^{\mathrm{a}}$ & $28.86 \pm 0.75^{\mathrm{a}}$ & $27.90 \pm 1.30^{\mathrm{a}}$ \\
STR $(\%)$ & $52.96 \pm 0.16^{\mathrm{a}}$ & $46.95 \pm 3.08^{\mathrm{b}}$ & $54.05 \pm 0.83^{\mathrm{a}}$ & $53.40 \pm 0.45^{\mathrm{a}}$ & $52.23 \pm 1.23^{\mathrm{a}}$ \\
WOB $(\%)$ & $54.46 \pm 0.03^{\mathrm{b}}$ & $49.10 \pm 1.85^{\mathrm{b}}$ & $59.90 \pm 0.96^{\mathrm{a}}$ & $54.03 \pm 1.05^{\mathrm{b}}$ & $53.33 \pm 1.23^{\mathrm{b}}$ \\
ALH $(\%)$ & $3.56 \pm 0.06^{\mathrm{a}}$ & $3.27 \pm 0.32^{\mathrm{ab}}$ & $2.85 \pm 0.15^{\mathrm{b}}$ & $3.40 \pm 0.20^{\mathrm{ab}}$ & $3.36 \pm 0.03^{\mathrm{ab}}$ \\
BCF $(\mathrm{Hz})$ & $2.70 \pm 0.10$ & $3.15 \pm 0.08$ & $3.80 \pm 0.56$ & $3.10 \pm 0.41$ & $3.16 \pm 0.23$ \\
Vital rate $(\%)$ & $5.00 \pm 0.06^{\mathrm{b}}$ & $16.75 \pm 1.85^{\mathrm{a}}$ & $24.86 \pm 1.77^{\mathrm{a}}$ & $7.90 \pm 0.66^{\mathrm{b}}$ & $25.00 \pm 0.1^{\mathrm{a}}$ \\
HOST $(\%)$ & $6.50 \pm 0.00^{\mathrm{b}}$ & $24.20 \pm 4.20^{\mathrm{a}}$ & $25.15 \pm 3.3^{\mathrm{a}}$ & $21.16 \pm 4.1^{\mathrm{a}}$ & $26.27 \pm 3.15^{\mathrm{a}}$ \\
Total defect (\%) & $24.41 \pm 10.7$ & $20.22 \pm 3.08$ & $14.17 \pm 4.07$ & $17.25 \pm 7.7$ & $9.23 \pm 0.10$ \\
Acrosome integrity (\%) & $83.70 \pm 1.7$ & $80.67 \pm 2.48$ & $85.60 \pm 2.70$ & $79.95 \pm 3.47$ & $84.76 \pm 0.0$ \\
Pregnancy rate (\%) & $0.0 \%(0 / 12)^{\mathrm{b}}$ & $8.33 \%(1 / 12)^{\mathrm{b}}$ & $50.0 \%(6 / 12)^{\mathrm{a}}$ & $0.0 \%(1 / 12)^{\mathrm{b}}$ & $50.0 \%(5 / 10)^{\mathrm{a}}$
\end{tabular}

a, b, ab subscript represent significant difference at $P<0.05$ among groups in the raw.

Table 3: $\mathrm{pH}$, viscosity and osmolarity of Tris extender supplemented with GA or EY at room temperature.

\begin{tabular}{lccc}
\hline Extender & $\mathrm{pH}$ & Viscosity (cP) & $\begin{array}{c}\text { Osmolarity } \\
\left(\mathrm{mOsmol}^{\mathrm{kggH}} \mathrm{O}\right)\end{array}$ \\
\hline Distiled water & 5.6 & $3.65 \pm 0.55$ & -7 \\
EY (2.5\%) & 7.2 & $2.66 \pm 0.69$ & $381.07 \pm 1.80$ \\
GA (3\%) & 7.1 & $3.30 \pm 0.43$ & $360.50 \pm 1.88$ \\
GA (6\%) & 7.1 & $4.15 \pm 0.14$ & $400.50 \pm 4.5$ \\
GA (9\%) & 7.0 & $5.37 \pm 0.07$ & $408.33 \pm 2.37$ \\
GA (12\%) & 7.0 & $10.40 \pm 0.30$ & $445.67 \pm 3.48$ \\
\hline
\end{tabular}

study, addition of GA could also alter the movement pattern of Buck spermatozoa.

Significantly higher $(P<0.05)$ vitality rate was obtained in extender with GA ( 6 and $9 \%$ ) and EY. Although the percentage of sperm defects was higher in GA extenders compared to EY extender, the difference between extenders was insignificant (Table 2). As it is known the cooling and freezing process promoted irreversible cellular injuries resulted in impair the semen fertility. In addition the physical characteristics of the solution like its viscosity and osmolarity might have an impact on the sperm motility and ability for fertilization. Plasma membrane integrity (HOST) was significantly higher $(P<0.05)$ in extender with 6,9 and $12 \%$ of GA or $2.5 \%$ of EY extender than with $3 \%$ of $A G$. The plasma membrane allows important molecules pass through to the sperm cytoplasm. As well integrity of plasma membrane is very important for the interaction between the male and female gametes (Tosti and Ménézo, 2016). The superiority of GA and EY by the HOST and biometric testing suggested that it might provide better protection for the plasma membrane during deep freezing.

The pregnancy rate $(50 \%)$ using semen that was frozen in GA $(9 \%)$ was similar to EY extender $(2.5 \%)$. Pregnancy rate derived of $\mathrm{Al}$ in small ruminants still beyond the acceptable values. Egg yolk has been extensively used for long time as a cryoprotectant in the semen extenders. Several risk factors are inherited with the use of EY as a biological material. Therefore GA inclusion in Tris extender affords significance on buck's subsequent fertility outcomes. The lesser fertility rate of frozen semen with $3 \%$ of GA resulted in low motility rate, low survival rate and high morphological defect, especially tailless. This may be due to less protection of GA (3\%) extender during freezing. There were no pregnant ewes when using $12 \%$ GA. The lesser fertility rate following $12 \%$ of $G A$ is due to a low survival rate in sperm after deep freezing.

\section{CONCLUSION}

Inclusion of GA as a cryoprotectant at 6- $9 \%$ in the buck semen extender resulted in a relatively a good approach for maintaining buck sperm motility, survival and subsequent fertility. In addition, it surpassed the EY in this trait and subsequent avoids the harmful effect of EYCE enzyme and the infective risk that might arise from using $E Y$ in the semen extender. 


\section{REFERENCES}

Amann, R.P. and Graham, J.K. (1993). Spermatozoa Functional. In: Equine Reproduction.1.ed. Philadelphia: [Mckinnon, A.O.; Voss, J.L. (Eds.)] Lea and Febiger. 715-745.

Amann, R.P. and Hammerstedt, R.H. (1980). Validation of a system for computerized measurements of spermatozoal velocity and percentage of motile sperm. Biology of Reproduction. 23: $647-656$.

Anand, M., Yadav, S. and Shukla, P. (2014). Cryoprotectant in semen extender: From egg yolk to low-density lipoprotein (LDL). Review Article. Livestock Research International. 2: 48-53.

Beir, J., Boulais, M., Gallego, V., O'Brien, J.K., Peixoto, S., Robeck, T.R. and Cabrita, E. (2019). Sperm handling in aquatic animals for artificial reproduction. Theriogenology. 133: 161-178.

Evans, G. and Maxwell, W.M.C. (1987). Handling and Examination Semen. In: Salamon's Artificial Insemination of Sheep and Goat. Butterworths, [Maxwell, W.M.C. (Ed.)] Sydney. p. 93-106.

Fonseca, J.F., Torres, C.A.A., Maffili, V.V., Borges, A.M., Santos, A.D.F., Rodrigues, M.T. and Oliveira, R.F.M. (2005). The hypoosmotic swelling test in fresh goat spermatozoa. Animal Reproduction. 2: 139-144.

García, W., Tabarez, A. and Palomo, M.J. (2017). Effect of the type of egg yolk, removal of seminal plasma and donor age on ram sperm cryopreservation. Animal Reproduction. 14: 1124-1132.

Hirai, M., Cerbito, W.A., Wijayagunawardane, M.P.B., Braun, J., Leidl, W., Ohosak, Q.K., Matsuzawa, T., Miyazawa, K. and Sato, K. (1997). The effect of viscosity of semen diluents on motility of bull spermatozoa. Theriogenology. 47: 1463-1478.

Hubalek, Z. (2003). Protectants used in the cryopreservation of microorganisms, Review. Cryobiology. 46: 205-229.

Lopez, E.C., Champion, D., Blond, G. and Le Meste, M. (2005). Influence of dextran, pullulan and gum arabic on the physical properties of frozen sucrose solutions. Carbohydrate Polymers. 59: 83-91.

Mohamed Ali, Musa, M.M., Alfadul, S. and Al-Sobayel, K. (2017). Consequences of adding gum Arabic as a cryoprotectant on motility and viability of frozen stallion semen. Cryobiology. 79: $21-28$.
Mohamed Ali, Musa, M.M., Alfadul, S. and Al-Sobayel, K. (2018). Effect of Gum Arabic on Stallion Sperm Survival during Cold Storage and Post Freezing. Macedonian Veterinary Review. 41: i-xi.

Montenegro, M.A., Boiero, M.L., Valle, L. and Borsarelli, C.D. (2012). Gum Arabic: More Than an Edible Emulsifier, Products and Applications of Biopolymers, Casparus Johannes Reinhard Verbeek, IntechOpen.

Muhammet, R.U., Abdelrahman, A.S., Evans, H.C., Gilmore, A.A., Hitit, M., Arifiantini, R.I., Purwantara, B., Abdullah, K. and Memili, E. (2019). Advances in Cryopreservation of Bull Sperm. Front Veterinary Science. 6: 1-15.

Ondøej, S., Jiøí, Š., Jan, B., Pavla, M.P., Lucie, T., Doležalová, M., Petra, F., Ludik, S. and Radko, R. (2019). Low Density Lipoprotein - important player in increasing cryoprotective efficiency of soybean lecithin-based bull semen extenders. Animal Reproduction. 16: 267-276.

Purdy, P.H. (2006). A review on goat sperm cryopreservation. Small Ruminant Research. 63: 215-225.

Ritar, A.J. and Salamon, S. (1982). Effects of seminal plasma and of Its removal and of egg yolk in the diluent on the survival of fresh and frozen-thawed spermatozoa of the Angora goat. Australian Journal of Biological Sciences. 35: 305-312.

Singh, A., Bhakat, M., Mondal, S., Mohanty, T.K., Behare, P., Mondal, G., Rahim, A., Yadav, S.K., Gupta, A.K., Gupta, M.D. and Abdullah, M. (2017). Microbial load of frozen thawed Sahiwal semen extended in egg yolk, soya lecithin and liposome based extender. Indian Journal of Animal Research. 52: 1-3.

Tosti, E. and Ménézo, Y. (2016). Gamete activation: basic knowledge and clinical applications. Human Reproduction Update. 22: 420-439.

Ugur, M.R., Saber Abdelrahman, A., Evans, H.C., Gilmore, A.A., Hitit, M., Arifiantini, R.I., Purwantara, B., Kaya, A. and Memili, E. (2019). Advances in Cryopreservation of Bull Sperm. Frontiers in Veterinary Science. 6: 268. 